\title{
Cartography, new technologies and geographic education: theoretical approaches to research the field
}

\author{
Tânia Seneme do Canto ${ }^{\mathrm{a}}$ \\ ${ }^{a}$ University of Campinas, Institute of Geosciences, Campinas, Săo Paulo, Brazil, taniacanto@ige.unicamp.br
}

\begin{abstract}
In order to understand the roles that digital mapping can play in cartographic and geographic education, this paper discusses the theoretical and methodological approach used in a research that is undertaking in the education of geography teachers. To develop the study, we found in the works of Lankshear and Knobel (2013) a notion of new literacies that allows us looking at the practices within digital mapping in a sociocultural perspective. From them, we conclude that in order to understand the changes that digital cartography is able to foment in geography teaching, it is necessary to go beyond the substitution of means in the classroom and being able to explore what makes the new mapping practices different from others already consolidated in geography teaching. Therefore, we comment on some features of new forms of cartographic literacy that are in full development with digital technologies, but which are not determined solely by their use. The ideas of Kitchin and Dodge (2007) and Del Casino Junior and Hanna (2006) are also an important reference for the research. Methodologically, this approach helps us to understand that in the seek to comprehend maps and their meanings, irrespective of the medium used, we are dealing with a process of literacy that is very particular and emergent because it involves not only the characteristics of the map artifact and of the individual that produces or consumes it, but depends mainly on a diversity of interconnections that are being built between them (map and individual) and the world.
\end{abstract}

Keywords: Mapping practices, New literacies, Digital technologies, Education, Geography teaching

\section{Introduction}

As taught by Edney (1993), cartography is the result of multiple cartographic practices that have been delineated and transformed from transient and diverse social, cultural and technological relations. Thus, it is possible to affirm that, in some way, the changes that we live today affect the way we produce and consume maps. In cartography, this process contributes to its continuing expansion and the proposing of new questions to investigate.

Some of the questions posed in this new context are directly related to the characteristics acquired by mapping with the development of digital technologies and the place that this new cartography can occupy in geographic education. It seems clear that new technologies have enabled original ways of making and using maps, promoting new modes of representing and thinking about space, however, we still know very little about where this can lead us when our focus is set on education. What possibilities and limits do these new maps and practices offer to geography and cartography teaching? How can we design for schools the creative ruptures that this new cartographic landscape has already been presenting to the world outside schools?

Faced with these concerns, in the present work we discuss the references we have been mobilizing in the development of the research project entitled "Cartography and Digital Technologies: new literacies in geography teaching (?)". The objective of the discussion is to deal with some theoretical-methodological concepts and approaches that, in our view, present important contributions to this new field of research, which aims to understand the educational processes associated with contemporary digital cartography, as well as the roles it may assume in school geography and cartography.

\section{A research on cartography, new technologies and geography teaching}

As already mentioned, the research we are developing is called "Cartography and digital technologies: new literacies in geography teaching (?)" and the question mark we place between parentheses at the end of the title tells a lot about the assumptions that support it. At the same time that we identify in digital cartography a new literacy with a great potential for education and teaching, we are still in the process of knowing what we can really do with it in this area. Thus, we understand that it is fundamental to keep the discussion open, questioning in the research the real possibility of this new cartography to contribute to another kind of education.

The previous researches and readings (Canto 2010, 2014) we have made indicate that through the application of the new technologies, mapping has become a practice marked by the forms of communication and interaction associated with the digitization of information. Not only did the format of maps change from analog to digital, but also their modes of construction, reading, interpretation, and use. Thus, the ways in which we produce meaning for maps 
are no longer the same, and therefore a new form of literacy has emerged with cartography from digital technologies.

But what does this matter in geography teaching? What can this new cartographic language change in the teaching of the discipline in school? What new processes of signification can it provide for teachers and students? At last, which senses map making under the conditions of new technological context may assume in geography teaching?

With these questions in the background, the ongoing research has a qualitative character and it is being developed in the teacher training, as part of the Degree in Geography of the Institute of Geosciences of the University of Campinas, Săo Paulo, Brazil. In this way, focusing on the processes, knowledge and meanings involved in the interaction of future geography teachers with the cartography made possible by digital technologies, the specific objectives of the study are:

- To identify and to understand the practices and knowledge mobilized and requested by the digital mappings when future geography teachers engage with them.

- To understand the ways of thinking and experiencing the cartography, the digital technologies and the space that such engagements promote.

- To comprehend the factors and technological aspects that influence the production of new senses for maps, for space and for geography teaching.

In order to reach these objectives, we take as a theoretical-methodological basis the understanding of Lankshear and Knobel (2013) on the relationship between new literacies and digital technologies, as well as the conception of map developed by Kitchin and Dodge (2007) and Del Casino Junior and Hanna (2006). In our view, the approximation between these two perspectives allows us to move in new studies and understandings on the demands and effects of digital cartography for geography teaching and geographic education in a broader way.

\section{Digital technologies as language: the ontological sense of new literacies and their implications for education}

According to Lankshear and Knobel (2013), the term new literacies has been used as a conceptual umbrella to designate different practices performed with digital technologies. In this way, every multimedia artifact that can be read, written, interpreted and signified by people in their day-to-day life are commonly apprehended by the term. As the authors claim (Lankshear et al. 2013, 1) "as a general classification, 'new literacies' typically refers to interactions with digitized textual material and other digital media".

By establishing that any practice of literacy with digital technologies can be conceived as new, the term new literacies ends up receiving a chronological focus. Thus, the meaning of new is directly associated with the novelty of the means and not with the elaborated processes of meaning production. It is true that the updating of information and communication technologies allows the emergence of new forms of interaction with different types of texts, however, their use is not always enough to guarantee such novelty, in the same way that a new practice of literacy is not solely associated with a technological innovation.

Thinking about this, Lankshear and Knobel propose to understand the new literacies from an ontological perspective, which implies that the new literacies are not new simply because they refer to recent practices or because they happen through new information and communication technologies; but because they made possible forms of communication and interaction that are significantly different from those that already exist. Thus, the authors seek to conceive new literacies as practices that are increasingly mediated by digital technologies, but do not necessarily presuppose their use: "within this ontological sense of new literacies we included forms of literacy practice that were emerging in association with new technologies, along with others that might or might not involve the use of new technologies" (Lankshear and Knobel, 2013, 7).

A good example that makes us realize the importance of the ontological meaning in understanding the new literacies refers to the increasing use of non-linguistic semiotic systems, such as icons and images, in everyday reading, writing and speaking practices in contemporary times. As Lankshear et al. $(2013,2)$ explain, "there is no necessary association with digital technology use here, although a strong and growing contingent association exists."

In this sense, to understand the new literacies associated with digital technologies, it is not enough to consider only the interactions that occur directly with them. Undoubtedly, this is an essential dimension, however, not enough to identify and understand what is really new in the literacy practices made possible by the new technologies, among which we include the mapping practices that we are so interested about in our research.

Thinking about new literacies in education, Lankshear and Knobel (2013) point out two aspects that need to be taken into account in studies and research. The first one involves the way in which new technologies are conceived and used in schools and the second recognizes the importance of practices that occur outside the school space.

According to the authors, in contexts of technological change, practices with new technologies are strongly influenced by existing practices and routines, and the modes of appropriation that take place in school obey the same principle: "established literacies changed only to the extent that they were now sometimes done with word processors rather than pencils" (Lankshear and Knobel 2013 , 8). Therefore, we must be attentive to these processes when we try to find the continuities and 
ruptures promoted in engagements with digital technologies in the classroom.

Regarding the second aspect, Lankshear and Knobel (2013) state that although school practices are not very innovative when they come into contact with new technologies, in other instances their presence makes emerge practices that are significantly different from those that existed previously. In doing so, they emphasize the need for educators and education researchers to keep up with the disruptions that occur in the world beyond the classroom so that they are able to bring them also into it.

We recognized that if literacy practices in education are to stay in touch with the world beyond the classrooms, educators must become informed about creative disruptions and not merely adapt new technologies to familiar practices and routines. This calls for ongoing work that aims to map and understand such evolutions and project them to educational audiences. (Lankshear and Knobel 2013, 8).

Thus, in order to overcome what Barreto (2003) calls conservative modernization in educational appropriation of technologies, it is important to understand that the simple substitution of means is not capable of promoting one of the most significant changes that digital technologies can offer to education, namely: the transformation of the model of communication itself, that is, the literacies that have been sustaining school practices. For this, it is not enough to update the tools we use in the classroom, it is necessary to understand how the new ones are different from the ones already in use and how we can explore such differences in the school context.

\section{New cartographic literacies: changes in the world of maps}

In the case of cartography, this ontological perspective allows us to perceive forms of literacy that are in full development with the new technologies, but which are not determined solely by its use. As Dodge et al. (2009) point out, cartography nowadays is experiencing a kind of renaissance, marked by the emergence of a complex and creative network of mappings and ways of interpreting them. in contemporary cartographic epistemologies, a diverse range of mappings is seen to emerge from a shifting creative milieu, the end result of which is not a unidirectional evolutionary tree of maps, but rather a complex, many branching, rhizomatic structure. (Dodge et al. 2009, 312).

In this scenario well characterized by the authors, we identified three processes that digital technologies have strengthened in the cartography field. We deal with them below, but first, it is worth emphasizing that each of these new features of contemporary cartography can't be seen in isolation. It is possible to separate these phenomena to analyze them, however, in reality, they are strongly interwoven, making the practices of literacy with maps nowadays quite complex.

\subsection{Co-mapping}

The first process refers to the deep permeability and interaction between the moments of production and consumption of the maps. In most cases, when the cartographic representations reach us through the screens of the various devices that surround us, it is not only at our eyes that they are directed, but also at our actions. The maps that circulate in cyberspace today are already produced counting on our participation to take place, and even when they are not thought of in this format, it is still possible to transform them through different remixing practices.

Although some authors (Del Casino Junior and Hanna 2006) emphasize that production and consumption are always intertwined in mapping practice, there is no doubt that new technologies, due to the characteristics of their language and operating mechanisms, led to the dissolution of this frontier to an even greater level, calling into question the authorship of the maps themselves. According to Cartwright $(2008,11)$, the evolution of Web has brought about a radical change in the authoral character of maps, since, "users would construct their own mapping product from both cartographer-provided components and their own information". Dodge et al. $(2009,317)$ also inform us about this phenomenon in the following passage:

Significant changes in notions of authorship are at the heart of many contemporary modes of mapping. In particular there is a fracturing of authorship with the emergence of a more "writerly" kind of mapping (following Roland Barthes), which according to Pickles (2004, 161) can 'engage the reader as an "author" and insist upon the openness and intertextuality of the text'. Moreover many aspects of map-making practices are undergoing a metamorphosis towards a "remix" cultural model of production that is apparent in many other media (cf. Bolter and Grusin 1999; Diakoopoulos et al. 2007), in which new media constantly reinterpret existing media in a process facilitated by rapid and unconstrained access.

Thus, through the expansion of interactivity and the paths that information can take, new technologies have made it possible for the consumer or map user to acquire a greater production capacity, which is reflected in the growing engagement of people in collaborative mapping and the creation of new maps from the reinterpretation of other pre-existing ones.

\subsection{Equations, Symbols and Units}

Another process that has marked the new cartographic literacies and has ascended with the digital technologies can be characterized by the intense articulation of the cartographic language with other languages, including the programming ones. It is quite evident that the maps we interact with today are not only made up of points, lines, polygons, and legend. They are permeated by different forms of texts, images, sounds, videos and, also, algorithms.

This mixture of languages, which does not only affect maps, but different modes of expression and 
communication of contemporary culture, results in the generation of new languages, or, species of signs, as Santaella (2007) puts it.

Specifically in the field of cartography, this means that the language of maps is gaining new possibilities of representation of spaces and places.

Exactly because of its capacity to produce new signs, Santaella (2007) understands the articulation of languages promoted by the new technologies as a process of hybridization. This understanding of the author emphasizes that both the convergence of the media and the non-linear combination of several existing sign types contribute to the expansion of languages. She says (Santaella 2007, 132) that in fact, there could be no better qualification than hybrids for blends of media, under the name "multimedia", and for blends between systems of different signs and distinct languages, configured in hypertextual structures, under the name "hypermedia".

With the continuous evolution of software, applications and the codes behind them, forms of integration of languages and media are also being reinvented, and new and sophisticated sign mixes are circulating in cyberspace every day. In some applications created with maps it is like if the cartographic language itself, at least as we traditionally know it, has acquired a certain transparency and was penetrated by other languages. Thus, we may not see points, lines, and polygons in these new forms of mapping, but the maps are there, invisibly territorializing the various other signs that articulate them.

In this context, the term hybrid used by Santaella (2007) aims precisely to indicate the various and complex possibilities of combining languages made effective in the new technologies, which gives to text, sound, image and also to the map a deep instability and fluidity.

\subsection{Ubiquitous cartography}

Another aspect that we would like to highlight related to the new forms of literacy in the field of cartography is the remarkable mobility and ubiquity associated with maps since the appearance of so-called mobile technologies. With the possibility of association between digital information and geographical location, maps began to have more participation in the subjects' daily practices, accompanying their movements through space and transforming their relations with the "real" and virtual world.

Mainly due to the emergence of devices with connection properties to the internet and the Global Positioning System (GPS), applications and technologies designed to promote the integration of cyberspace with geographic space are growing every day. Due to the new spatiality they are able to produce, such applications have aroused the interest of several authors, who have been referring to them as locative media.

According to Lemos (2008), locative media can be classified into different types, considering the function they play, however, a characteristic common to all of them is "the emission of digital information from places/objects". He explains (Lemos 2008, 207) that locative media are used to aggregate digital content to a locality, serving for functions such monitoring, surveillance, mapping, geoprocessing (GIS), location, annotation, or gaming. In this way, places and objects begin to dialogue with information devices, sending, collecting and processing data from a close relationship between digital information, location and mobile digital artifacts.

But what do the maps have to do with it? They have become a privileged language in this process by efficiently allowing the linking of information and location. Even if the access or the sending of digital information from places or objects does not occur through maps displayed on the screens of mobile devices, there is a geographic mapping of data underlying any locative media application. This is why Dodge et al. (2009) argue that, increasingly, mapping is found as part of the digital interfaces, if not when it is itself the interface which can be consulted.

As the authors have pointed out, the digital interfaces associated with mapping were already a reality before the dissemination and popularization of mobile technologies, but their use was very restricted to military purposes. In contemporary times, however, they participate intensely in our daily experiences.

this interface between person, map, and the world in motion would once have been reserved for specialised and particularly

military applications, but is now the everyday experience for many when walking with a mobile phone, driving with a satnav, flying with the airshow maps on an inflight entertainment system, and even playing with handheld GPS units in treasure hunting games of geocaching. (Dodge 2009, 313).

Given this, we may say that such phenomenon certainly causes profound changes in our way of thinking and relating to maps and spaces. Why would this not affect our way of teaching and learning geography?

\section{Maps in process: investigating practices and geographies}

In order to understand how the forms of literacy associated with digital cartography can also produce changes in the teaching of geography, we consider Lankshear and Knobel's (2013) guidelines regarding the care we should take with educational research interested in new literacies. According to them, caution is needed against very applied and goal-oriented studies from the outset, since the phenomenon under investigation is very recent and requires, from the field of literacy studies itself, the renewal of ideas to understand the changes that are occurring. Faced with this, the authors advocate a type of research that they call Let's see, which is "is undertaken largely for its own sake, with the primary aim of understanding in depth a 'new' social practice and the literacies associated with or mobilized within this practice [...] from the perspectives and sensibilities of "insiders"” (Lankshear and Knobel 2013,9). 
Our research goes along with this more open and perspective focused on subjects, setting the dialogue with some authors that have presented a more processual and contextualized look for cartography. This look has allowed us to see maps no longer as a fixed and closed form, but as an unstable artifact, filled with entrances and exits that are constituted in the interaction of individuals with the maps and the world.

As Kitchin and Dodge (2007) think, maps are not, they become maps by people's practices. The knowledge, questions, skills and experiences mobilized by them that bring maps "into being". Therefore, for these authors, maps must always be taken and investigated as mappings in process, that is, representations never finished or defined, constantly made and remade by spatially and temporally situated practices.

Maps are of-the-moment, brought into being through practices (embodied, social, technical), always remade every time they are engaged with; mapping is a process of constant reterritorialization. As such, maps are transitory, fleeting, being contingent, relational and context-dependent. Maps are practices - they are always mappings; spatial practices enacted to solve relational problems (...). (Kitchin and Dodge 2007, 335)

Taking a close approach to Kitchin and Dodge (2007), Del Casino Junior and Hanna (2006) also argue that maps and mappings are not limited to their material aspects. More than a product, they are the result of connections with other representations and experienced spaces. That is, as with different types of representation, the authors (Del Casino Junior and Hanna 2006, 37) say maps are "sensed objects/subjects mediated by the multiplicity of knowledges we bring to and take from them through our everyday interactions and representational and discursive practices".

Methodologically, this approach helps us to understand that in the seek to understand maps and their meanings, irrespective of the medium used, we are dealing with a process of literacy that is very particular and emergent because it involves not only the characteristics of the map and of the individual that produces or consumes it, but depends mainly on a diversity of relationships that are being constructed between them (map and subject) within a given context. In this perspective, as stated by Del Casino Junior and Hanna (2006, 51), “our objects of analyses are not simply maps but are instead the myriad interconnections that make production and consumption of map spaces a process of both authoring and reading simultaneously".

In addition to showing us that in the interaction of subjects with maps, creation and interpretation always cross paths, the aforementioned authors also teach us, through the term map spaces, that cartographic representations are inseparable from the performances and experiences of people with the space and vice versa:

Thinking about map spaces in this way means neither the production nor the consumption of maps is separable from space in the most mundane of settings. Maps that people simultaneously make and use mediate their experiences of space. [...] At the same time, spaces mediate people's experiences of maps. (Del Casino Junior and Hanna, 2006, 44).

This way of understanding the connection between map and space is especially relevant to our study, due to the possibilities that it presents to also understand, through maps, the new literacies of the geographic space. Thus, when considering the process of signification associated with digital maps, we are also questioning the spatiality produced and consumed in the contemporary world, which is increasingly interconnected with cyberspace and digitalization.

\section{Conclusion}

The role of cartography in geography teaching and the way in which maps spatially educate us in contemporary times are issues that have being receiving the attention of various authors and scientific events in Brazil and across the world. To a great extent, the interest and concern in discussing and investigating this theme are linked to the influence of the current technological means in the field of cartography. As we have pointed out, digital technologies have introduced significant changes in the way we map, in the cartographic representations we create, and in the modes and contexts that we use them. With this, it is not only expected, as it is essential that we seek to understand the possibilities and demands of this new cartography focused on education.

In order to do so, we rely on theoretical thrusts that not only support the field of research, but that, in particular, make it possible to produce new understandings about the relationship between cartography, new technologies and geographic education. As we link the conceptual approach of Lankshear and Knobel (2013) on new literacies and Kitchin and Dodge (2007) / Del Casino Junior and Hanna (2006) on maps, we believe that we are treading a very productive path in research, which will allow the advancement of knowledge in this field.

Such a conclusion is based on the understanding that the meanings of digital mapping in geographic education are not yet given and to foster them we must first understand the forms of literacy that new mapping practices engender in the educational process. The ontological leaning of the concept of new literacies helps us to fulfill this task by showing the importance of exploring what makes the new mapping practices different from the already consolidated ones in geography teaching, whereas the procedural vision of cartography helps us to investigate maps as practices and no longer as products, besides allowing that, together with the new cartographic literacies, we can also see the geographies that we can teach and learn in the contemporary world.

\section{Acknowledgements}

We are grateful to FAPESP - Săo Paulo Research Foundation and to the research group named Atelier of Research and Practices in Geography Teaching, from the Institute of Geosciences, University of Campinas. Our work is funded in FAPESP under the process number $16 / 16121-0$. 


\section{References}

Barreto, R. G. (2003). As TIC na educaçăo: das políticas ŕs práticas de linguagem. DataGramaZero, 4(5). http://www.brapci.ufpr.br/brapci/_repositorio/2010/01/p df_d0acade178_0007525.pdf. Acessed 10 June 2016.

Canto, T. S. (2010). A cartografia na era da cibercultura: mapeando outras geografias no ciberespaço. Dissertation - (master). Rio Claro, SP: Universidade Estadual Paulista, Instituto de Geocięncias e Cięncias Exatas. http://hdl.handle.net/11449/95555. Acessed 15 January 2017.

Canto, T. S. (2014). Práticas de mapeamento com as tecnologias digitais: para pensar a educaçăo cartográfica na contemporaneidade. Thesis - (doctorate). Rio Claro, SP: Universidade Estadual Paulista, Instituto de Geocięncias e Cięncias Exatas. http://hdl.handle.net/11449/123662. Acessed 15 January 2017.

Cartwright, W. (2008). Delivering geospatial information with Web 2.0. In: M. P. Peterson (Ed.), International perspectives on maps and the Internet (pp. 11-30). New York: Springer.

Del Casino Junior, V., Hanna, S. P. (2006). Beyond the "binaries": a methodological intervention for interrogating maps as representational practices. ACME: An International E-Journal for Critical Geographies, 4(1), 34-56.

Dodge, M., Perkins, C., Kitchin, R. (2009). Mapping modes, methods and moments: a manifesto for map studies. In: M. Dodge, C. Perkins, R. Kitchin (Orgs.), Rethinking Maps (pp. 311-341). London: Routledge.

Edney, M. (1993). Cartography without 'progress': reinterpreting the nature and historical development of mapmaking. Cartographica: The International Journal for Geographic Information and Geovisualization, 30(2/3), 54-68.

Kitchin, R., Dodge, M. (2007). Rethinking maps. Progress in Human Geography, 31(3), 331-344. http://phg.sagepub.com/cgi/content/refs/31/3/331. Acessed 10 March 2016.

Lankshear, C., Knobel, M. (2013). Introduction: social and cultural studies of new literacies from an educational perspective. In: C.

Lankshear, M. Knobel, M. (Ed.), A new literacies reader: educational perspectives (pp. 1-19). New York: Peter Lang.

Lankshear, C., Knobel, M., Curran, C. (2013). Conceptualizing and researching "new literacies". In: C. A. Chapelle (Ed.), The Encyclopedia of Applied Linguistics (pp. 1-8), Oxford: Wiley-Blackwell.

Lemos, A. (2008). Mídias locativas e territórios informacionais. In: L. Santaella, L., P. Arantes (Orgs.), Estéticas tecnológicas: Novos modos de sentir (pp. 207230). Săo Paulo: Educ.

Santaella, L. (2007). Linguagens líquidas na era da mobilidade. Săo Paulo: Paulus. 